\title{
Hypofractionated Radiation Therapy with Temozolomide for Patients with Glioblastoma Multiforme Recursive Partitioning Analyzes Class V and VI
}

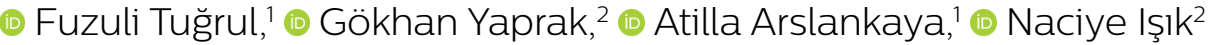

'Department of Radiation Oncology, Yunus Emre State

Hospital, Eskişehir, Turkey

${ }^{2}$ Department of Radiation Oncology, University of Health Sciences, Kartal Dr. Lütfi Kırda Training and Research Hospital İstanbul, Turkey

Submitted: 21.01.2019 Accepted: 09.05.2019

Correspondence: Fuzuli Tuğrul, Yunus Emre Devlet Hastanesi, Radyasyon Onkolojisi Kliniğ Eskişehir,Turkey

E-mail: tugruldrfuzuli@gmail.com

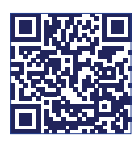

Keywords: Glioblastoma multiforme; hypofraction; radiation therapy; temozolomide.

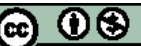

This work is licensed under a Creative Commons This work is licensed

\begin{abstract}
Objective: This study was performed to determine whether adjuvant temozolomide and $45 \mathrm{~Gy} / \mathrm{I} 5 \mathrm{fr}$ hypofractionated radiotherapy (RT) can be used to shorten the treatment duration in glioblastoma multiforme (GBM) patients with poor prognostic factors (Recursive Partitioning Analyzes (RPA) categories V, VI), without increasing the dose and toxicity and without risking the survival.
\end{abstract}

Methods: Patients older than 50 years, with histological diagnosis of GBM, who were in either RPA class $\mathrm{V}$ or $\mathrm{VI}$ were included in this retrospective single-arm single-center study. Patients were treated with a tumor dose of 45 Gy in 15 daily fractions in 15 treatment days in three weeks, together with concomitant temozolomide and adjuvant temozolomide.

Results: A total of 43 patients were included in this study. RT was completed as planned in full dose in all patients. No grade 3 acute toxicity due to hypofractionated RT was observed. Concomitant temozolomide was also used in all patients without dose lowering while adjuvant temozolomide as six cycles was applied in 27 patients, but in 12 of them, temozolomide dose was lowered due to hematological toxicity. Median overall survival was found as 10.5 months, and I-year overall survival proportion was $42 \%$. The median progression-free survival time was 8.4 months.

Conclusion: While no decrease in expected survival with hypofractionated radiotherapy and temozolomide was detected, no increase in toxicity was observed.

\section{INTRODUCTION}

High-Grade Gliomas are the most commonly encountered primary brain tumors in adults and Glioblastoma multiforme (GBM) is one of the most rapidly progressing and fatal tumor in high-grade gliomas. ${ }^{[1]}$ Surgery plus chemotherapy and radiotherapy (RT) are the gold standard treatment of GBM. ${ }^{[2]}$ Postoperative radiotherapy is usually administered with 2 Gy daily fractions in six weeks. Improvement in survival was achieved with chemotherapy added to radiotherapy; however, five-year survival is very low (9.8\%). ${ }^{[3,4]}$ In these patients with short survival expectation, a shorter duration of treatment has been considered, and hypofractionated RT schedules were studied. In a randomized study reported by Poland et al. 44 patients with GBM who were treated with three split courses of hypofractionated RT to a total dose of $50 \mathrm{~Gy} .{ }^{[5]}$ Patients with GBM treated with hypofractionated RT regimen, had a better prognosis in comparison to the conventionally fractionated group with the two-year survival rates being $23 \%$ and $10 \%$, respectively. In elderly GBM patients treatment with a shorter hypofractionated radiotherapy course demonstrated similar survival and palliative benefit compared to a standard 6-week course (overall survival 5.6 versus 5.1 months, $p=0.57$ ) in the study reported by Roa et al. ${ }^{[6]}$

The RT schedule in Stupp study, which demonstrated the survival advantage of temozolomide addition was conventionally fractionated RT. ${ }^{[3,4]}$ Since hypofractionated radiation regimens in the above-mentioned studies had similar outcomes with conventional radiation, hypofractionated radiation was thought to be combined with temozolomide to achieve similar results in GBM patients. When the adjuvant 
temozolomide is added to the short term radiotherapy ( 30 $\mathrm{Gy} / 6 \mathrm{Fr}$ ), it resulted in a statistically significant survival benefit (versus hypofractionated RT) with minimal additional toxicity in elderly patients. ${ }^{[7,8]}$ Barker et al..$^{[9]}$ reported that concomitant temozolomide with either conventional or hypofractionated RT significantly improved survival of poor prognostic patients with GBM. In series using concomitant and adjuvant temozolomide with hypofractionated radiotherapy regimens, treatment was well-tolerated and comparable to conventional treatment. ${ }^{[10-13]}$

Significant survival advantage in doses over 45 Gy was reported in GBM. ${ }^{[14]}$ However, although there was an increase in toxicity, the survival advantage was not confirmed in high dose studies. ${ }^{[15,16]}$ Therefore, we aimed to have shorter overall treatment time in poor prognosis GBM patients without increasing total radiation dose with the addition of temozolomide to hypofractionated RT. Thus, this retrospective study was performed to determine whether Stupp schema ${ }^{[4]}$ of adjuvant temozolomide and $45 \mathrm{~Gy} / \mathrm{I} 5 \mathrm{fr}$ hypofractionated RT can be used to shorten the treatment duration in GBM patients with poor prognostic factors (Recursive Partitioning Analyzes (RPA) categories $\mathrm{V}, \mathrm{VI}$ ), without increasing the dose and toxicity, and without risking the survival.

\section{MATERIALS AND METHODS}

The efficacy of the concomitant application of adjuvant temozolomide with hypofractionated RT was investigated in patients with GBM in this prospective single-arm single-center study. All patients provided written informed consent, and this study was approved by the institutional ethics committee.

In patients with pathological diagnosis of GBM, the type of surgical resection was evaluated with the computed tomography (CT) or magnetic resonance imaging (MRI) and surgical epicrisis; and classified as total resection, subtotal resection or biopsy. Residual tumor after surgery was defined as gross tumor volume (GTV).

Radiotherapy was applied to the patients in two phases. In phase I, total $30 \mathrm{~Gy}$ in 10 fractions to Planning Target Volume (PTV) $(\mathrm{GTV}+2.5+0.5 \mathrm{~cm})$ and in phase 2, $300 \mathrm{cGy} /$ fr 15 Gy in 5 fractions, a total dose of 45 Gy to PTV boost $(\mathrm{GTV}+\mathrm{I}+0.5 \mathrm{~cm})$ was applied. RT was planned with dedicated CT and three-dimensional planning systems; conformal RT was delivered with linear accelerators with photon energy of $6 \mathrm{MV}$.

The dosage of temozolomide during the procedure was in accordance with the regimen of Stupp et al. ${ }^{[4]}$ Temozolomide at a dose of $75 \mathrm{mg} / \mathrm{m}^{2} /$ day together with RT was used per oral for 19-2I days. Four weeks after the end of RT, adjuvant temozolomide treatment began at a dose of I50$200 \mathrm{mg} / \mathrm{m}^{2} /$ day for $1-5$ days and repeated every 28 days for six cycles. Clinical evaluation was undertaken every week during RT, every month during adjuvant temozolomide treatment and repeated at the end of $3^{\text {rd }}$ and $6^{\text {th }}$ regimens via $C T$ or $M R I$. The primary efficacy endpoint was overall survival from the date of surgery. The secondary endpoint was progression-free survival that defined as the duration from the date of the surgical therapy to the date of radiologically detected progression; however, it should be taken into account that pseudo-progression cases could not have been excluded. It was decided that if radiological progression would have been detected in the first three months, therapy would not be terminated as long as the performance of the patient was appropriate and temozolomide was fully applied for six months. In addition, the impact of age, gender, KPS, surgery type and RPA class (Table I) on overall survival time was investigated.

\section{Statistical analysis}

Statistical analyses were performed using Software Package for Social Sciences (SPSS). For subgroup comparisons, Chi-square test, for univariate analysis of progression-free and overall survival calculation Kaplan-Meier method and multivariate survival analysis Cox regression test were used. Survival comparisons were made by the Log-rank test. Toxic effects were evaluated according to Radiation Oncology/Toxicity Grading (RTOG) criteria. Level of statistical significance was $\mathrm{p}<0.05$.

\section{RESULTS}

A total of 43 patients were included in this study. Patient characteristics are presented in Table 2. The mean age of the patients was 62 (min-max 50-85) years; 23 (53.5\%) patients were males. Surgery extent was total resection in $20(46 \%)$, subtotal resection in $12(28 \%)$, biopsy only in I I (26\%) patients.

RT was completed as planned in full dose in all patients (100\%). The steroid was used in all patients, and it was ter-

Table I. Radiation therapy oncology group (RTOG) recursive partitioning analyzes (RPA) categories ${ }^{[17]}$

\begin{tabular}{ll}
\hline RPA III & Age $<50$, anaplastic astrocytoma and abnormal \\
& mental status \\
& Age $<50$, glioblastoma multiforme and KPS \\
& $90-100$ \\
& Age $<50$, glioblastoma multiforme and KPS $<90$ \\
RPA IV & Age $>50$, glioblastoma multiforme, KPS 70-100 \\
& partial / total resection and good neurological \\
& function \\
& Age $\geq 50$, glioblastoma multiforme, KPS 70-100 \\
and presence of neurological deficit that decreases \\
RPA V & Anctional capacity due to surgical resection \\
& minimum 54 Gy RT with biopsy only \\
& Age $\geq 50$, KPS $<70$, normal mental status \\
RPA VI & Age $\geq 50$, KPS $<70$, abnormal mental status, \\
& Age $\geq 50$, glioblastoma multiforme, KPS 70-100, \\
& biopsy only and RT lower than 54 Gy
\end{tabular}

KPS: Karnofsky performance status; RT: Radiotherapy. 
minated with dose lowering after RT. Median eight-week steroid use was needed from the initiation of RT (2-22 weeks). No grade 3 acute toxicity due to hypofractionated RT was observed. As a delayed side effect of radiation, radiation necrosis was diagnosed upon radiologic examination in two patients; however, histological confirmation was not performed. During radiochemotherapy, anemia developed in five (12\%), neutropenia in eight (18\%), and grade 2 thrombocytopenia in five (12\%) patients.

Concomitant temozolomide was also used in all patients without dose lowering while adjuvant temozolomide as six cycles was applied in 27 patients (64\%), but in 12 (28\%) of them, temozolomide dose was lowered due to hematological toxicity. Adjuvant chemotherapy was terminated before planned in three $(7 \%)$ patients because of grade 4 neutropenia $(n=1)$, grade 4 thrombocytopenia $(n=1)$ and deep vein thrombosis and thrombocytopenia $(n=1)$. In 13 (29\%) patients, chemotherapy was terminated due to progression. The median number of temozolomide cycles was noted as 5 (range $=1-6$ ).

Patients who could not complete adjuvant temozolomide treatment were evaluated according to patient characteristics. None of the patients with RPA VI were noted to complete chemotherapy while 9 of 36 patients with RPA V $(25 \%)$ could not complete the planned therapy $(p<0.00 \mathrm{I})$. In 13 of 24 patients (54.6\%) with $\leq 70$ Kernofsky Performance Status (KPS), and three of 19 patients (16.0\%) with better KPS (16\%), six cycles of adjuvant temozolomide could not be applied. Therefore, significantly fewer patients with low $(\leq 70)$ KPS and RPA VI completed the treatment $(p=0.02)$. The findings showed that there was

Table 2. Patient characteristics and median survival time

\begin{tabular}{|c|c|c|c|c|}
\hline & \multirow[b]{2}{*}{$\mathbf{n}$} & \multirow[b]{2}{*}{$\%$} & \multicolumn{2}{|c|}{ Overall survival time } \\
\hline & & & $\begin{array}{c}\text { Median } \\
\text { (months) }\end{array}$ & $\mathbf{p}^{*}$ \\
\hline \multicolumn{5}{|l|}{ Age (years) } \\
\hline $50-64$ & 25 & 58 & 12.8 & 0.030 \\
\hline$\geq 65$ & 18 & 42 & 9.7 & \\
\hline \multicolumn{5}{|l|}{ Gender } \\
\hline Female & 20 & 46.5 & 10.1 & 0.700 \\
\hline Male & 23 & 53.5 & 12.7 & \\
\hline \multicolumn{5}{|l|}{ KPS } \\
\hline $90-100$ & II & 26 & 14.8 & 0.020 \\
\hline 80 & 16 & 37 & 11.3 & \\
\hline$\leq 70$ & 16 & 37 & 7.7 & \\
\hline \multicolumn{5}{|l|}{ Surgery } \\
\hline Total excision & 20 & 46 & 10.5 & 0.600 \\
\hline Subtotal excision & 12 & 28 & 9.5 & \\
\hline Biopsy & II & 26 & 6.1 & \\
\hline \multicolumn{5}{|l|}{ RPA } \\
\hline V & 36 & 84 & 12.7 & $<0.001$ \\
\hline VI & 7 & 16 & 4.7 & \\
\hline
\end{tabular}

KPS: Karnofsky performance status; RPA: Recursive Partitioning Analyzes.

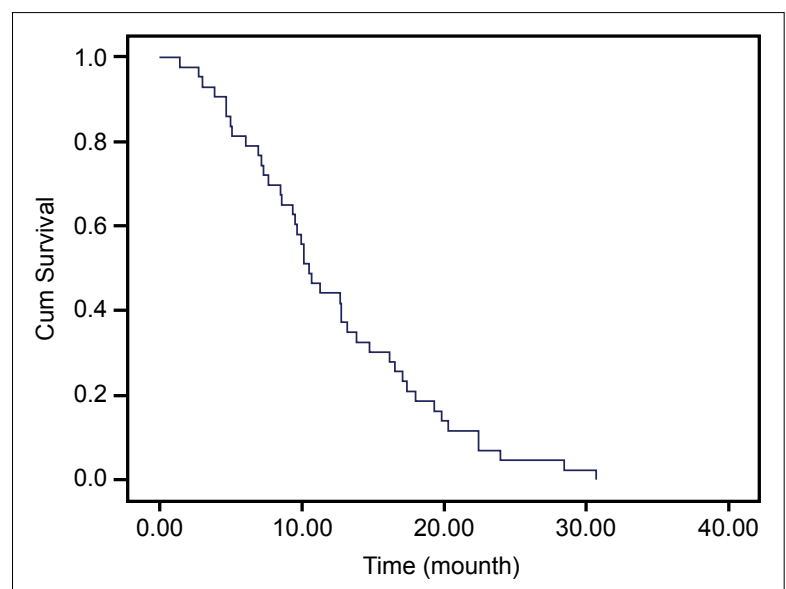

Figure 1. Overall survival.

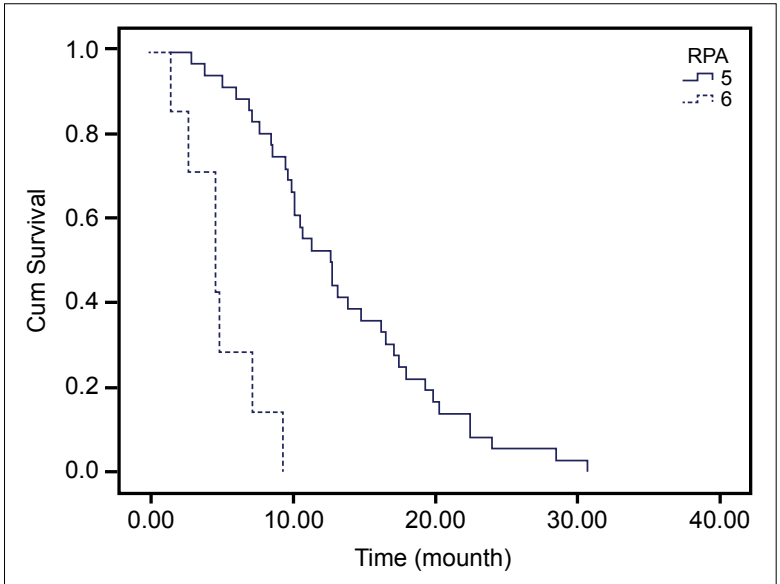

Figure 2. Survival according to RPA scoring.

no relationship between age, gender, and surgery type and treatment compliance. Median follow-up in all patients was 12 months (range $=\mid .5-3 \mathrm{I}$ months). All patients died during the analysis process.

In all patients, median survival time after the operation was found as 10.5 (range=8.8-12.3) months (Fig. I); and I-year overall survival proportion was $42 \%$. The median progression-free survival time was 8.4 (range=7.6-9.2) months, and I-year survival proportion was $26 \%$.

Age, gender, KPS, surgery type, and RPA category were evaluated as prognostic factors affecting survival with univariate and multivariate analysis. Upon univariate analysis, overall survival time was significantly longer in younger patients $(p=0.03)$, in the patients with higher KPS $(p=0.02)$ and in RPA 5 patients $(p<0.00 \mathrm{I})$ (Table 2; Fig. 2). Similarly, in multivariate analysis, age, KPS and RPA category were found to be among prognostic factors on survival. No effects of gender and surgery type were found on overall survival.

\section{DISCUSSION}

RTOG RPA classification system has been developed in the early 1990s and has been validated in multiple clin- 
ical trials in GBM. Prognostic factors based on the RPA classification system were studied in three RTOG trials, including 1578 patients with GBM or anaplastic astrocytoma. ${ }^{[17,18]}$ Patient's age, the surgery type and performance status were reported to be the most important prognostic factors in these studies. For GBM, four groups with a median survival of I7.9, II.I, 8.9 and 4.6 months were identified. In the study by Lin et al., ${ }^{[19]}$ simplified model to the updated GBM database application defined three distinct classes with median survival times of I7.I, II.2, and 7.5 months for Classes III, IV, and V+VI, respectively. GBM patients with RPA $\vee$ and $\mathrm{VI}$ categories have limited survival expectations, and these patients may need new treatment alternatives, such as shorter duration radiotherapy for palliation in patients with poor prognosis. Hence, $45 \mathrm{~Gy} / \mathrm{I} 5 \mathrm{fr}$ $300 \mathrm{cGy} / \mathrm{fr}$ radiotherapy and concomitant adjuvant temozolomide treatment was tried in our study; older age ( $\geq 65$ years), lower (<70) KPS, RPA category 6 were determined as poor prognostic factors; and the overall survival was found to be 10.5 month that was not worse compared to previous studies in those patients.

Indeed, several studies in the last decade evaluated the effectiveness of shorter RT regimens in GBM patients with unfavorable characteristics. In historical series, 6-month survival was obtained with $30 \mathrm{~Gy} / \mathrm{l}$ ofr, $30 \mathrm{~Gy} / 6 \mathrm{fr}, 40 \mathrm{~Gy} / 8$ $\mathrm{fr}, 28 \mathrm{~Gy} / 4 \mathrm{fr}$ RT schemes, in patients with poor prognosis. ${ }^{[20-22]}$ Slotman et al. reported the results of a non-randomized study with 30 patients, $42 \mathrm{~Gy} / 14 \mathrm{fr}$ scheme have a median survival II.5 months in patients with age $<50$ years, KPS 80-100 and total resection and 6.5 months in patients with age $>50$ years, KPS $<70$ and subtotal resection. ${ }^{[23]}$ Kleinberg et al. reported eight months of survival in patients with RPA V and 5IGy /I7fr RT scheme and five months of survival in RPA VI and 2I Gy/7 Fr RT scheme. [24] Chang et al. reported that they found similar results in RPA IV-VI GBM patients treated with 50Gy/20 Fr RT as seven months median survival when compared to the results RTOG studies according to RPA scale. ${ }^{[25]}$ In all of these studies, different schemes were used and it was reported that hypofractionated RT was tolerable, provided similar survival to standard RT; and could be preferred in patients with poor prognostic factors.

Stupp et al. ${ }^{[3]}$ compared RT (60 Gy/30 fr) with RT plus temozolomide in 573 GBM patients in a randomized study and found that median survival was 12 months in RT arm and I5 months in RT plus temozolomide arm $(p<0.00 \mathrm{I})$. As a result of this study, this treatment schema became the new standard treatment approach in GBM. In our study, 10.5 months overall survival achieved with temozolomide scheme having survival advantage evidence, added to hypofractionated RT is lower than that of Stupp study. However, patients younger than 70 years and ECOG I-2 were included in Stupp study; this difference may be considered to be depending on worse prognostic factors rather than hypofractionation.

Raymond et al. ${ }^{[10]}$ have applied $60 \mathrm{~Gy}$ in 20 fractions to the tumor location with IMRT concomitant boost tech- nique and 40 Gy to the tumor periphery, together with concomitant and adjuvant chemotherapy. Overall survival of I4.4 months was found to be similar to conventional RT temozolomide studies. In RPA V-VI groups, median survival was 12.9, and disease-free survival was eight months. Weis et al. ${ }^{[1]}$ acquired 8.2 months survival with concomitant and adjuvant temozolomide with $40 \mathrm{~Gy}(2.67 \mathrm{~Gy} / \mathrm{fr})$ in 65 years and older patients and commented that it is comparable to conventional treatments and well-tolerated. Teresaki et al. ${ }^{\left[{ }^{[2]}\right]}$ achieved 15.6 months survival using temozolomide with concomitant $45 \mathrm{~Gy} / \mathrm{I} 5 \mathrm{Fr}, 12$ cycles of adjuvant temozolomide. There was no worsening in life quality determined by KPS and FACT-Br Subscale scores with this procedure. Chen ${ }^{[13]}$ used $60 \mathrm{~Gy}$ hypofractionated intensitymodulated radiotherapy (IMRT) with 3-6 Gy/fr, together with concomitant and adjuvant temozolomide treatment. Median survival of 16.2 months was obtained in KPS $>60$ patients with smaller than $6 \mathrm{~cm}$ targets without brain stem invasion. In our study, the survival of 12.7 months in RPA five patients is similar to those studies. Survival of 4.7 months obtained in RPA VI patients was thought as there is a requirement for another treatment scheme.

In Stupp study ${ }^{[3]}$ that led temozolomide to be the standard treatment in GBM, among the 287 patients who were assigned to receive concomitant RT (60 Gy/30 Fr) plus temozolomide, $85 \%$ completed both RT and temozolomide as planned. Thirty-seven patients (13\%) prematurely discontinued temozolomide because of toxic effects (in 14 patients), disease progression (in II), or other reasons (in I2). In our study, planned therapy with $50 \%$ shorter radiochemotherapy could be applied to all patients. In Stupp study, adjuvant temozolomide was stopped due to toxicity in $8 \%$, disease progression in $39 \%$; thus, $47 \%$ completed six regimens. However, in our study, adjuvant temozolomide was stopped due to toxicity in $7 \%$, and due to progression in $29 \%$, thus $64 \%$ completed six regimen. The application of hypofractionated chemoradiotherapy scheme was better than standard chemoradiotherapy, and application of adjuvant chemotherapy was similar.

Terasaki et al. ${ }^{[12]}$ applied $30 \mathrm{~Gy} / \mathrm{I} 5 \mathrm{Fr}$ RT with concomitant chemotherapy to all patients similar to our study. Adjuvant chemotherapy in this study was completed as 12 cycles in $19 \%$ of the patients. Raymond et al. ${ }^{[10]}$ did not note acute toxicity except for grade 3-4 emesis in one patient of RPA V-VI group with hypofractionated RT plus concomitant and adjuvant temozolomide; late toxicity was noted in none of the patients, and $83 \%$ of the patients completed concomitant chemoradiotherapy. In the study by Weiss, ${ }^{[1]}$ of the patients $(n=24)$ older than 65 years, underwent 40 Gy RT 2.6 Gy/Fr with concomitant adjuvant temozolomide, 23 completed radiochemotherapy, and 15 completed adjuvant chemotherapy. In three patients, they encountered 3-4 hematological toxicity during adjuvant chemotherapy. Chen's ${ }^{[13]}$ study was a prospective Phase I trial to systematically escalate the radiation fraction size from $3 \mathrm{~Gy}$ through to $6 \mathrm{~Gy}$ (total $60 \mathrm{~Gy}$ ) with concurrent and adjuvant temozolomide. All ( 16 patients) patients 
completed concurrent RT and temozolomidechemotherapy except for one patient, for unrelated to the study treatment. Similar to our study, the compliance of the patients in those hypofractionated radiochemotherapy plus chemotherapy studies was considerably favorable. The factors for our patients not completing the treatment were RPA being VI and KPS being 70 and lower. The case that none of the RPA VI patients could have completed planned therapy gave rise to the thought that choices of best supportive care, hypofractionated RT or only temozolomide should be evaluated in this group of patients.

Chen et al. ${ }^{[13]}$ detected brain necrosis in three of 16 patients after $60 \mathrm{~Gy}$ with 3-6 Gy/fr. One patient with vision loss had a tumor in close proximity to the optic nerve and chiasm, indicating that this treatment regimen might not be appropriate for tumors in close proximity to the optic structures. Morganti et al. ${ }^{[26]}$ carried out a dose-escalation study with hypofractionated RT with IMRT with concomitant and adjuvant temozolomide in 19 patients. None of the patients experienced dose limited toxicity. Grade I-2 treatment-related neurologic and skin toxicity were common (II and 19 patients, respectively). Grade $>2$ late neurologic toxicities were noted in none of them. The rate of freedom from late neurotoxicity at 12 and 24 months was $94.7 \%$ and $82.9 \%$, respectively.

In the study by Floyd et al. ${ }^{[27]}$ with intensity-modulated radiation therapy (IMRT), a dose of 50 Gy was delivered in 5-Gy daily fractions within two weeks to enhancing primary disease, residual tumor, or surgical cavity. Of the I5 patients evaluated for late toxicity, three $(20 \%)$ patients required reoperation for radiation necrosis. They reported that brain necrosis probability is increased with this schema. In our study, necrosis was seen in two (5\%) patients radiologically, and surgery was performed to none of them. These hypofractionated schemes performed with IMRT concomitant boost technique are more conformal than our 3D RT technique. Although it might be even possible to give hypofractionated RT safely, care should be taken for these patients. For patients with a relatively better prognosis, long-term side effects of hypofractionation may become a problem and should therefore not be given.

In conclusion, the addition of temozolomide to hypofractionated RT in the selected patient group decreased the treatment duration by $50 \%$ while overall survival has not been affected in our study. Hypofractionated RT has advantages over standard RT in patients with a life expectancy of months like GBM, and this is an important concern regarding the quality of life owing to the significant time commitment required to undergo RT. This regimen offers a treatment course that is completed in three, instead of six weeks, which may be preferable in certain subsets of patients (such as RPA V-VI) when palliation is the primary treatment goal. At the same time, it has the advantage of lower-cost due to decreased RT duration over standard therapy.

Ethics Committee Approval

Approved by the local ethics committee.
Informed Consent

Retrospective study.

Peer-review

Internally peer-reviewed.

Authorship Contributions

Concept: N.I.; Design: G.Y.; Supervision: N.I.; Materials: F.T.; Data: A.A.; Analysis: N.I.; Literature search: A.A.; Writing: F.T.; Critical revision: N.I.

Conflict of Interest

None declared.

\section{REFERENCES}

1. DeAngelis LM. Brain tumors. N Engl J Med 2001;344:114-23

2. Sathornsumetee S, Reardon DA, Desjardins A, Quinn JA, Vredenburgh JJ, Rich JN. Molecularly targeted therapy for malignant glioma. Cancer 2007;110:13-24. [CrossRef]

3. Stupp R, Mason WP, van den Bent MJ, Weller M, Fisher B, Taphoorn $\mathrm{MJ}$, et al. Radiotherapy plus concomitant and adjuvant temozolomide for glioblastoma. N Engl J Med 2005;352:987-96. [CrossRef]

4. Stupp R, Hegi ME, Mason WP, van den Bent MJ, Taphoorn MJ, Janzer RC, et al. Effects of radiotherapy with concomitant and adjuvant temozolomide versus radiotherapy alone on survival in glioblastoma in a randomised phase III study: 5-year analysis of the EORTC-NCIC trial. Lancet Oncol 2009;10:459-66. [CrossRef]

5. Gliński B. Postoperative hypofractionated radiotherapy versus conventionally fractionated radiotherapy in malignant gliomas. A preliminary report on a randomized trial. J Neurooncol 1993;16:16772. [CrossRef]

6. Roa W, Brasher PM, Bauman G, Anthes M, Bruera E, Chan A, et al. Abbreviated course of radiation therapy in older patients with glioblastoma multiforme: a prospective randomized clinical trial. J Clin Oncol 2004;22:1583-8. [CrossRef]

7. Muni R, Minniti G, Lanzetta G, Caporello P, Frati A, Enrici MM, et al. Short-term radiotherapy followed by adjuvant chemotherapy in poor-prognosis patients with glioblastoma. Tumori 2010;96:60-4.

8. Minniti G, De Sanctis V, Muni R, Rasio D, Lanzetta G, Bozzao A et al. Hypofractionated radiotherapy followed by adjuvant chemotherapy with temozolomide in elderly patients with glioblastoma. J Neurooncol 2009;91:95-100. [CrossRef]

9. Barker CA, Chang M, Chou JF, Zhang, Z, Gutin PH, Beal K, et al. Concurrent Temozolomide (TMZ) improves survival, but increases toxicity, in elderly patients with Glioblastoma Multiforme (GBM) treated with Standard (STD) or Abbreviated (ABR) Radiotherapy (RT). Int J Radiat Oncol Biol Phys 2010;78:S167. [CrossRef]

10. Panet-Raymond V, Souhami L, Roberge D, Kavan P, Shakibnia L, Muanza T, et al. Accelerated hypofractionated intensity-modulated radiotherapy with concurrent and adjuvant temozolomide for patients with glioblastoma multiforme: a safety and efficacy analysis. Int J Radiat Oncol Biol Phys 2009;73:473-8. [CrossRef]

11. Weiss SE, Cheung A, Drappatz J. Hypofractionated radiotherapy with temozolomide for elderly patients with glioblastoma Int J Radiat Oncol Biol Phys 2010;78:S271. [CrossRef]

12. Terasaki M, Eto T, Nakashima S, Okada Y, Ogo E, Sugita Y, et al. A pilot study of hypofractionated radiation therapy with temozolomide for adults with glioblastoma multiforme. J Neurooncol 2011;102:247-53. [CrossRef]

13. Chen C, Damek D, Gaspar LE, Waziri A, Lillehei K, KleinschmidtDeMasters BK, et al. Phase I trial of hypofractionated intensity-modulated radiotherapy with temozolomide chemotherapy for patients 
with newly diagnosed glioblastoma multiforme. Int J Radiat Oncol Biol Phys 2011;81:1066-74. [CrossRef]

14. Bleehen NM, Stenning SP. A Medical Research Council trial of two radiotherapy doses in the treatment of grades 3 and 4 astrocytoma. The Medical Research Council Brain Tumour Working Party. Br J Cancer 1991;64:769-74. [CrossRef]

15. Tsien C, Moughan J, Michalski JM, Gilbert MR, Purdy J, Simpson J, et al. Phase I three-dimensional conformal radiation dose escalation study in newly diagnosed glioblastoma: Radiation Therapy Oncology Group Trial 98-03. Int J Radiat Oncol Biol Phys 2009;73:699-708.

16. Chan JL, Lee SW, Fraass BA, Normolle DP, Greenberg HS, Junck LR, et al. Survival and failure patterns of high-grade gliomas after threedimensional conformal radiotherapy. J Clin Oncol 2002;20:1635-42.

17. Curran WJ Jr, Scott CB, Horton J, Nelson JS, Weinstein AS, Fischbach AJ, et al. Recursive partitioning analysis of prognostic factors in three Radiation Therapy Oncology Group malignant glioma trials. J Natl Cancer Inst 1993;85:704-10. [CrossRef]

18. Scott CB, Scarantino C, Urtasun R, Movsas B, Jones CU, Simpson $\mathrm{JR}$, et al. Validation and predictive power of Radiation Therapy Oncology Group (RTOG) recursive partitioning analysis classes for malignant glioma patients: a report using RTOG 90-06. Int J Radiat Oncol Biol Phys 1998;40:51-5. [CrossRef]

19. Li J, Wang M, Won M, Shaw EG, Coughlin C, Curran WJ Jr, et al. Validation and simplification of the Radiation Therapy Oncology Group recursive partitioning analysis classification for glioblastoma. Int J Radiat Oncol Biol Phys 2011;81:623-30. [CrossRef]

20. Bauman GS, Gaspar LE, Fisher BJ, Halperin EC, Macdonald DR, Cairncross JG. A prospective study of short-course radiotherapy in poor prognosis glioblastoma multiforme. Int J Radiat Oncol Biol Phys 1994;29:835-9. [CrossRef]

21. Thomas R, James N, Guerrero D, Ashley S, Gregor A, Brada M. Hypofractionated radiotherapy as palliative treatment in poor prognosis patients with high grade glioma. Radiother Oncol 1994;33:113-6. [CrossRef]

22. Hulshof MC, Schimmel EC, Andries Bosch D, González González D. Hypofractionation in glioblastoma multiforme. Radiother Oncol 2000;54:143-8. [CrossRef]

23. Slotman BJ, Kralendonk JH, van Alphen HA, Kamphorst W, Karim AB. Hypofractionated radiation therapy in patients with glioblastoma multiforme: results of treatment and impact of prognostic factors. Int J Radiat Oncol Biol Phys 1996;34:895-8. [CrossRef]

24. Kleinberg L, Slick T, Enger C, Grossman S, Brem H, Wharam MD $\mathrm{Jr}$. Short course radiotherapy is an appropriate option for most malignant glioma patients. Int J Radiat Oncol Biol Phys 1997;38:31-6.

25. Chang EL, Yi W, Allen PK, Levin VA, Sawaya RE, Maor MH. Hypofractionated radiotherapy for elderly or younger low-performance status glioblastoma patients: outcome and prognostic factors. Int J Radiat Oncol Biol Phys 2003;56:519-28. [CrossRef]

26. Morganti AG, Balducci M, Salvati M, Esposito V, Romanelli P, Ferro $\mathrm{M}$, et al. A phase I dose-escalation study (ISIDE-BT-1) of accelerated IMRT with temozolomide in patients with glioblastoma. Int J Radiat Oncol Biol Phys 2010;77:92-7. [CrossRef]

27. Floyd NS, Woo SY, Teh BS, Prado C, Mai WY, Trask T, et al. Hypofractionated intensity-modulated radiotherapy for primary glioblastoma multiforme.. Int J Radiat Oncol Biol Phys 2004;58:721-6. [CrossRef]

\section{RPA Skoru V ve VI Olan Glioblastom Hastalarında Temazolamidle Hipofraksiyone Radyoterapi}

Amaç: Bu çalışma, kötü prognostik faktörlere (Recursive Partitioning Analyzes -RPA- skor V, VI) sahip glioblastome multiforme (GBM) hastalarında dozu ve toksisiteyi arttırmadan ve sağkalımı azaltmadan, adjuvan temozolamid ve 45 Gy/l5 fr hipofraksiyone radyoterapi (RT) rejiminin, tedavi süresini kısaltmak için kullanılıp kullanılamayacağını belirlemek için yapıldı.

Gereç ve Yöntem: Bu geriye dönük tek kollu ve tek merkezli çalısmaya; 50 yaşından büyük GBM histolojik tanılı, RPA skoru V veya VI olan hastalar dahil edildi. Hastalara, üç haftada 15 fraksiyonda 45 Gy RT, eşzamanlı temozolamid ile birlikte uygulandı. Radyoterapi sonrası adjuvan temozolamid ile tedaviye devam edildi.

Bulgular: Çalışmaya toplam 43 hasta alındı. Tüm hastalar planlanan dozda RT'yi tamamladı. Hipofraksiyone RT nedeniyle grade 3 akut toksisite gözlenmedi. Eşzamanlı temazolamid bütün hastalarda doz azaltılmaksızın uygulandı. Akabinde altı kür adjuvan temozolamid alan 27 hastanın I2'sinde gelişen hematolojik toksisite nedeniyle doz azaltılmasına gidildi. Ortanca genel sağkalım 10.5 ay ve bir yıllık genel sağkalım oranı \%42 idi. Ortanca progresyonsuz sağkalım süresi 8.4 aydı.

Sonuç: Hipofraksiyone radyoterapi ve eşzamanlı temozolamid ile sağkalımda bir azalma gözlenmezken, toksisitedede bir artış izlenmedi.

Anahtar Sözcükler: Glioblastoma multiforme; hipofraksiyanasyon; radyoterapi; temozalamid. 